\title{
PENERAPAN SISTEM PEMBAGIAN PENDAPATAN PADA BANK MUDHARABAH NAGARI SYARIAH CABANG PADANG
}

\author{
Rini Setiawati, Ratna Widayati \\ Akademi Keuangan dan Perbankan Padang \\ ratnawidayati@akbpstie.ac.id
}

\begin{abstract}
Bank Nagari Syariah Cabang Padang is one of the islamic banks to raise fund in the system using mudharabah. Mudharabah is a collaboration between two parties where one party acts as financier (sahubul maal) one party more as a fund manager (mhudarib), in cooperation mudharabah do system for the result if the profit will be shared with the agremeent at the beginning, whereas if you exsperience loss then based on the condition that the losses borne by the property instead of the manager. Mudharabh is divided into two kinds of mudharabah muthlakah that is fund management is spacious and muqayadah its fund management for specific purposes only. As for the pupose of this study was to determine how the aplication system for results on a mudharabah fund Bank Nagari Syariah Cabang Padang. Based on an analysis conducted by the method of observation, literature review and in-dept interview it can be seen that the Bank Nagari Syaria branch meadow implement a system for the result to savings mudharabah with 45:55 ratio, with the ratio of 65:35 mudharabah banks have received bonuses wadiah $30 \%$.
\end{abstract}

Keywords : Aplication Of Revenue Sharing System And Fund Raising

\section{PENDAHULUAN}

Islam sebagai pedoman hidup manusia, merupakan agama yang tidak hanya berkaitan dengan masalah ritual, akan tetapi merupakan sistem yang komprehensif dan mencakup seluruh aspek kehidupan, termasuk masalah industri keuangan sebagai salah satu motor penggerak roda perekonomian.

Undang-Undang No.21 tahun 2008 tentang perbankan syariah dan PP RI Pasal 19 ayat (1) No.72 tahun 1992 tentang bank berdasarkan prinsip bagi hasil serta dikeluarkan nya fakta bunga haram dari Majelis Ulama Indonesia (MUI) tahun 2003. Banyak bank yang menjalankan operasionalnya secara prinsip syariah dengan diperkenalkannya jenis bank dengan prinsip bagi hasil. Maka dalam 
sistem perbankan Indonesia selain bank umum yang di kenal selama ini, dapat pula memiliki kegiatan usaha berdasarkan sistem bagi hasil.

Basarkan kaidah Al mudharabah, yang berdasarkan prinsip ini, bank syari'ah akan berfungsi sebagai mitra, baik dengan penabung, dengan pengusaha yang meminjam dana. Dengan penabung, bank akan bertindak sebagai mudharib (pengelola), sedangkan penabung bertindak sebagai shohibul maal (penyandang dana). Antara keduanya di adakan akad mudharabah yang mengadakan keuntungan masing-masing pihak, di sisi lain pengusaha atau peminjam dana bank syari'ah akan bertindak sebagai shohibul maal (penyandang dana), baik yang berasal dari penabung ataupun deposito maupun dana bank sendiri berupa modal pemegang saham. Sementara itu, pengusaha atau peminjam akan berfungsi sebagai mudharib (pengelola) karena melakukan usaha dengan cara memutar dan mengelola dana bank. Oleh karena itu dibutuhkan sebuah upaya dalam mencapai target yang telah direncanakan pihak bank agar sesuai dengan prosedur yang telah ditetapkan.

Bank Nagari Syariah Cabang Padang merupakan salah satu bank syariah di Indonesia yang menjalankan konsep mudharabah berdasarkan Pernyataan Standar Akuntansi Keuangan(PSAK) 105. Bank Nagari Cabang Syariah Padang memberikan bantuan pembiayaan dalam bentuk pembayaran secara kredit atau cicilan dan mempunyai beberapa sistem, prosedur dan persyaratan yang harus dipenuhi oleh calon debitur. Jenis produk dana yang dikembangkan oleh Bank Nagari Syariah Cabang Padang adalah jenis produk mudharabah yang berlandaskan kepada system bagi hasil yang merupakan kegiatan yang banyak diminati oleh masyarakat diantaranya adalah Deposito Mudharabah. Sedangkan pembiayaan dilakukan dalam bentuk pemberian pinjaman.

Perumusan Masalah

Permasalahan yang akan dibahas berdasarkan latar belakang diatas adalah Bagaimana Penerapan Sistem Bagi Hasil Penghimpunan Dana Mudharabah Bank Nagari Syariah Cabang Padang.

Tujuan Penelitian

Penelitian ini bertujuan untuk mengetahui Penerapan Sistem Bagi Hasil Penghimpunan Dana Mudharabah Bank Nagari Syariah Cabang Padang. Metode Pengumpulan data

Penelitian ini dilakukan dengan membaca beberapa buku-buku ilmiah dan tulisan-tulisan yang berkaitan dengan pembahasan yang dilakukan dan peninjauan langsung objek penelitian untuk meneliti hasil data primer. 


\section{METODE ANALISA DATA}

Dalam menganalisa data, penulis menggunakan metode analisa data kualitatif menjelaskan secara deskriptif mengenai Penerapan system bagsi hasil penghimpunan dana mudharabah bank nagari syariah cabang Padang.

\section{LANDASAN TEORI}

\section{Pengertian Mudharabah}

Mudharabah adalah kerja sama antara dua pihak, dimana satu pihak, pemilik modal (shahibul maal) mempercayakan sejumlah dananya kepada pihak lain, yaitu pengusaha (mudharib) untuk menjalankan suatu aktivitas atau usaha, jika memperoleh keuntungan dibagikan sesuai dengan kesepakatan di awal, dan jika mengalami kerugian, maka ketentuannya berdasarkan syarat bahwa kerugian dalam mudharabah di bebankan kepada harta, tidak dibebankan sedikitpun kepada pengelola, Mudharabah dibagi menjadi 2 yaitu :

a. Mudharabah Muthlaqah

Mudharabah Muthlaqah adalah bentuk kerja sama antara penyedia modal (shahibul maal) dan pengelola modal (mudharib) yang cakupannya sangat luas dan lebih khusus seperti jenis usaha, waktu dan daerah yang akan digunakan untuk usahanya.

b. Mudharabah Muqayadah

Mudharabah Muqayadah yaitu kebalikan dengan Mudharabah Muthalaqah yaitu mudharib dibatasi batasan jenis usaha, waktu, dan tempat usahanya.

\section{Teori Bagi Hasil di Perbankan Syari'ah}

Dalam aplikasinya, mekanisme perhitungan bagi hasil dapat dilakukan dengan dua macam pendekatan, yaitu :

a Pendekatan Profit Sharing (Bagi Laba)

Perhitungan menurut pendekatan ini adalah perhitungan bagi hasil berdasarkan pada laba dari penegelola dana yaitu pendapatan usaha dikurangi dengan biaya usaha untuk memperoleh pendapatan tersebut.

b. Pendekatan Revenue Sharing (Bagi Pendapatan)

Perhitungan menurut pendekatan ini adalah perhitungan laba berdasarkan pada pendapatan yang diperoleh dari pengelola dana, yaitu pendapatan usaha sebelum dikurangi dengan biaya usaha untuk memperoleh pendapatan tersebut. 


\section{Konsep Bagi Hasil}

Konsep bagi hasil sangat berbeda dengan konsep bunga yang ditetapkan oleh sistem ekonomi konvensional. Dalam konsep bagi hasil terkandung hal-hal berikut:

a. Pemilik dana menambahkan dananya melalui intitusi keuangan yang bertindak sebagai pengelola dana.

b. Pengelola mengelola dana-dana tersebut dalam sistem yang dikenal dnegan sistem pool offund(penghimpun dana), selanjutnya pengelola akan menginvestasikan dana-dana tersebut dalam proyek atau usaha- usaha yang layak dan menguntungkan serta memenuhi semua aspek syari'ah.

c. Kedua belah pihak membuat kesepakatan (akad) yang berisi ruaang lingkup sama, jumlah nominal dana, nisbah, dan jangka waktu berlakunya kesepakatan tersebut.

\section{ANALISA DAN PEMBAHASAN}

\section{Macam-macam Produk Mudharabah Dalam Penghimpunan Dana Pada} Bank Nagari Syariah Cabang Padang

\section{a. Tabungan Mudharabah}

Tabungan adalah simpanan yang penarikan nya hanya dapat dilakukan menurut syarat tertentu yang disepakati, tetapi tidak dapat ditarik dengan cek atau alat yang dipersamakan dengan itu. Akuntansi untuk tabungan mudharabah dan penghimpunan dana bentuk lainnya menggunakan akad mudharabah pada dasarnya mengacu pada pernyataan standar akuntansi keuangan (PSAK) 105 tentang Akuntansi Mudharabah, khususnya yang terkait dengan akuntansi untuk pengelola dana. Berdasarkan pernyataan standar akuntansi keuangan (PSAK) 105, dinyatakan bahwa dana yang diterima dari pemilik dana (nasabah penabung) dalam akad mudharabah diakui sebagai dana syirkah temporer sebesar jumlah kas atau nilai wajar aset non-kas yang diterima. Pada akhir periode akuntansi, dana syirkah temporer diukur sebesar nilai tercatatnya.

\section{Sistem Perhitungan Bagi Hasil Tabungan Mudharabah}

Contoh :

Perhitungan bagi hasil individu rekening tabungan mudharabah dengan nisbah umum/normal pada perhitungan distribusi hasil usaha bulan april 2015 Tuan Abdul memiliki saldo rata-rata dalam rekeningnya sebesar Rp. 10.000.000 dan nisbah yang disepakati pada awal akad adalah 45\% untuk 
Tn. Abdul dan 55\% untuk bank syariah (mempergunakan nisbah umum) dari data tersebut bagi hasil yang diberikan kepada Tuan Abdul adalah sbb:

Perhitungan dengan rumus umum dan return dari kelomok dana adalah :

$$
\begin{aligned}
\text { bagi hasil } & =(\text { SRIR } \times \text { HBH } \times \text { RHPD }) /(365 \times 100) \\
& =(10.000 .000 \times 30 \times 4,10625) /(365 \times 100) \\
& =33.750
\end{aligned}
$$

Jadi, bagi hasil yang menjadi hal Tuan Abdul adalah 33.750

Keterangan :

SRIR : Saldo rata-rata dari masing-masing individu rekening tabungan mudharabah

HBH : Jumlah pembagian hasil usaha (sama dengan jumlah hari yang dipergunakan dalam perhitungan saldo rata-rata atau oerhitungan distribusi hasil usaha).

RHPD : Return hasil usaha pemilik dana yang dihasilkan dari perhitungan distribusi hasil usaha bulan yang bersangkutan. Perhitungan bagi hasil individu rekening tabungan dengan nisbah khusus/special nisbah.

Pada perhitungan distribusi hasil usaha bulan april 2003 Tuan zakaria memiliki saldo rata-rata dalam rekeningnya sebesar Rp 10.000.000 dan nisbah yang disepakati pada awal akad adalah $80 \%$ untuk Tuan Zakaria dan $20 \%$ untuk bank sedangkan nisbah umum yang berlaku untuk tabungan mudharabah adalah $45 \%$ untuk Tuan Zakaria dan 55\% untuk Bank syariah. Perhitungan dengan rumus umum dari return kelompok dana untuk selisih antara nisbah yang disepakati dengan nisbah umum dilakukan secara prposional sehingga perhitungan bagi hasil yang menjadi hak Tuan Zakaria adalah:

$$
\begin{aligned}
& \text { Nisbah normal }(45) \\
& \begin{aligned}
\text { Bagi hasil } & =(\text { SRR } \times \text { HBH } \times \text { RHPD }) /(365 \times 100) \\
= & (10.000 .000 \times 30 \times 4,10625) /(365 \times 100) \\
= & 33.750
\end{aligned} \\
& \text { Tambahan nisbah }(35) \\
& =80 / 20 \times 33.750=26.250 \\
& \text { Jumlah bagi hasil }=33.750+26.250 \\
& =60.000
\end{aligned}
$$

Tambahan bagi hasil dari nisbah tambahan sebsar Rp 26.250 menjadi tanggungan bank syariah sendiri dengan kata lain, ada nya nisbah khusus ini hasil bank syariah akan menjadi kecil. 


\section{b. Deposito Mudharabah}

Depisito adalah investasi dana berdasarkan akad mudharabah yang tidak bertentangan dengan prinsip syariah yang penarikannya hanya dapat dilakukan hanya pada waktu tertentu berdasarkan akad antara nasabah (penyimpan) dengan bank syariah (Unit Usaha Syariah). Perbedaannya dengan deposito konvensional adalah terlihat pada akad dan sistem bagi hasil yang ditawarkan.

\section{Sistem Perhitungan Sistem Bagi Hasil deposito Mudharabah}

Contoh:

Perhitungan deposito mudharabah pembayaran bagi hasil yang dilakukan setiap ulang tanggal investasi.

Pada tanggal 24 juni 2003 Tuang Ahmad menginvestasikan uangnya dalam bentuk deposito mudharabah sebesar Rp 5.000.000 untuk jangka waktu 1 bulan sengan nisbah 65 untuk Tuan Akhmad dan 35 untuk Bank syariah (nisbah normal). Bank mengambil kebijakan untuk membayarkan bagi hasil kepada deposan setiap ulang tanggal pembukaan investasi deposito mudharabah.

Perhitungan bagi hasil deposito mudharabah dengan rumus umum dengan return kelompok dana deposito mudharabah dan pembayaran bagi hasil dilkukan setiap tanggal mulai investasi (tanggal 24).

$$
\begin{aligned}
\text { Bagi hasil } & =(\text { SRIR } \times \text { HBH } \times \text { RHPD }) /(365 \times 100) \\
& =(5.000 .000 \times 30 \times 5,93125) /(365 \times 100) \\
& =24.375
\end{aligned}
$$

\section{c. Simpanan Giro}

Pengertian giro menurut Undang-Undang Perbankkan Nomor 10 Tahun 1998 tanggal 10 November 1998 adalah Simpanan yang penarikannya dapat dilakukan setiap saat dengan menggunakan cek, bilyet giro, sarana perintah lainnya atau dengan cara pemindah bukuan.

Secara umum, yang dimaksud dengan giro adalah cek, bilyet giro, sarana perintah bayar lainnya, atau dengan pemindah bukuan. Adapun yang dimaksud dengan giro syariah adalah giro yang dijalankan berdasarkan prinsip-prinsip syariah. Dalam hal ini, Dewan Syariah Nasional telah mengeluarkan fatwa yang menyatakan bahwa giro yang benar secara syariah adalah giro yang dijalankan berdasarkan prinsip wadiah dan mudharabah.

Yang dimaksud giro wadiah adalah giro yang dijalankan berdasarkan akad wadiah, yakni titipan murni yang setiap saat dapat diambil jika pemiliknya menghendaki. Dalam konsep wadiah yad al-dhamanah, pihak yang menerima 
titipan boleh menggunakan atau memanfaatkan uang atau barang yang dititipkan. Hal ini berarti wadiah yad dhamanah mempunyai implikasi hukum yang sama dengan qardh, yakni nasabah bertindak sebagai pihak yang meminjamkan uang dan bank bertindak sebagai pihak yang dipinjami. Dengan demikian, pemilik dana dan bank tidak boleh saling menjanjikan untuk memberikan imbalan atas penggunaan atau pemanfaatan dana atau barang titipan tersebut.

Dalam kaitannya dengan produk giro, Bank Syariah menerapkan prinsip wadiah yad dhamanah, yakni nasabah bertindak sebagai penitip yang memberikan hak kepada Bank Syariah untuk menggunakan atau memanfaatkan uang atau barang titipannya, sedangkan Bank Syariah bertindak sebagai pihak yang dititipi yang disertai hak untuk mengelola dana titipan dengan tanpa kewajiban memberikan bagi hasil dari keuntungan pengelolaan dana tersebut. Namun Bank Syariah diperkenankan untuk memberikan insentif berupa bonus (fee) dengan catatan tidak diperjanjikan sebelummnya.

Sistem Perhitungan Sistem Bagi Hasil giro Mudharabah

\begin{tabular}{|lc|l|l|l|}
\hline C & Uraian & \multicolumn{1}{|c|}{ Tabungan } & \multicolumn{1}{c|}{ Deposito } & \multicolumn{1}{c|}{ Giro } \\
\hline h & 2013 & Rp. 23.800.829.000 & Rp. 26.640.870.000 & Rp. 2.861.156.561 \\
\hline h & 2014 & Rp. 23.636.198.146 & Rp. 32.566.780.000 & Rp. 2.068.433.598 \\
\hline o & 2015 & Rp. 28.229.308.183 & Rp. 84.308.380.000 & Rp. 1.997.130.225 \\
\hline h & Total & Rp. 75.666.335.329 & Rp. 143.516.030.000 & Rp. 6.926.720.384 \\
\hline
\end{tabular}

Tn. Baris memiliki rekening giro wadiah di Bank Nagari Syariah Cabang Padang dengan saldo rata-rata pada bulan Mei 2015 adalah Rp 1.000.000,-Bonus yang diberikan Bank Nagari Syariah kepada nasabah adalah $30 \%$ dengan saldo rata-rata minimal Rp 500.000,-. Diasumsikan total dana giro wadiah di Bank Nagari Syariah adalah Rp 500.000.000,-. Pendapatan Bank Nagari Syariah dari penggunaan giro wadiah adalah Rp 20.000.000,Bonus yang diterima oleh Tn. Baris pada akhir bulan Mei 2015.

$$
\begin{aligned}
& \text { Bonus yang diterima } \\
& =\underline{\text { Rp. } 1.000 .000 \times \text { Rp. } 20.000 .000 \times 30 \%} \\
& =\text { Rp. } 500.000 .000 \\
& =\text { Rp 12.000 }
\end{aligned}
$$


Bank Nagari Syariah menyalurkan pembiayaan sebesar Rp.600.000.000 dengan keuntungan dari pembiayaan tsb adalah sebesar Rp16.000.000. jika pak hasan adalah salah satu nasabah yang memiliki giro di bank tersebut senilai Rp.25.000.000.

nisbah bagi hasil untuk giro adalah 20:80. dengan bobot giro 0,91. pendapatan yang diterima oleh pak hasan:

Pembiayaan $=$ Rp.600.000.000

Total pendapatan $=$ Rp. 16.000 .000

\section{Perkembangan Penghimpunan Dana Mudharabah Pada Bank Nagari Syariah Cabang Padang Tahun 2013 sampai 2015}

Dari tabel diatas dapat dilihat bahwa perkembangan penghimpunan dana yang dilakukan oleh Bank Nagari Cabang Syariah Padang berfluktuasi setiap tahunnya, artinya mengalami turun naik. Seperti penghimpunan dana dalam bentuk tabungan dari tahun 2013 sampai dengan 2014 mengalami penurunan dari Rp. 23.800.829.000 menjadi Rp. 23.636.198.146 hal ini disebabkan oleh kurang pahamnya masyarakat tentang bank syariah selain itu penurunan disebabkan oleh kalah saingannya Bank Nagari Syariah dalam mengambilnya nasabah dibandingkan dengan bank konvensional dan persaingan sesama bank syariah itu sendiri, dari tahun 2014 ke 2015 mengalami kenaikan jumlah tabungan dari Rp. 23.636.198.146 ke Rp. 28.229.308.183 kenaikan ini disebabkan gencarnya bank syariah dalam mempromosikan produk tabungan dikalangan masyarakat. Selanjutnya deposito mudharabah slalu mengalami kenaikan dari tahun 2013, 2014, 2015, dari jumlah Rp. 26.640.870.000 di tahun 2013, naik menjadi Rp. 32.566.780.000 di tahun 2014, hingga berakhir di 2015 dengan jumlah Rp. 84.308.380.000 hal ini disebabkan oleh keyakinan yang dianut oleh masyarakat padang yang mayoritas muslim selain itu pada deposito mudharabah, masyarakat dapat mengetahui keuntungan yang ia dapat dari persentase bagi hasil. Giro mudharabah slalu mengalami penurunan dari tahun 2013 sampai 2015 dari tahun 2013 Rp. 2.861.156.561 ditahun 2014, turun menjadi Rp. 2.068.433.598 hingga berakhir di 2015 dengan jumlah Rp. 1.997.130.225 hal ini disebabkan untuk giro mudharabah mengalami penurunan disebebkan karena, masyarakat yang menyimpan uang dengan rekening giro kurang, selain dilihat dari pencairan masyarakat yang banyak berjualan dipasar tidak memberikan rekening giro saat mereka bertransaksi, sektor yang mengunakan rekening giro saat mereka bertransaksi, sektor yang menggunakan rekening giro adalah sektor usaha menengah ke atas. 


\section{PENUTUP}

\section{Kesimpulan}

a. Penghimpunan dana pada Bank Nagari Syariah Cabang Padang sama halnya dengan Bank Konvensional seperti giro, tabungan, dan deposito, akan tetapi prinsip oprasional yang diterapkan dalam penghimpunan dana masyarakat adalah prinsip wadiah dan mudharabah. Adapun macam macam produk mudharabah dalam penghimpunan dana pada Bank Nagari Syariah Cabang Padang adalah sebagai berikut:

1). Tabungan Mudharabah

Pak abdul memiliki saldo rata rata 10.000.000 nisbah disepakati 45:55

$$
\begin{aligned}
\text { Bagi hasil } & =(\text { SRIR X HBH X RHPD) / (365X 100) } \\
& =(10.000 .000 \text { X } 30 \text { X 4,10625) / (365 X 100) } \\
& =33,750 \text { bagi hasil yang diterima tuan amir }
\end{aligned}
$$

2). Deposito Mudharabah

Tanggal 23 juni Tuan Ahmad menginvestasikan deposito mudharabah Rp. 5.000.000 jangka waktu 1 bulan nisbah 65:35,

$$
\begin{aligned}
\text { Bagi hasil }= & (\text { SRIR X HBH X RHPD }) /(365 \text { X 100) } \\
& =(5.000 .000 \times 30 \times 5,93125) /(365 \times 100) \\
& =24,375
\end{aligned}
$$

3). Simpanan Giro

Tuan baris memiliki giro wadiah dengan saldo rata-rata bulan Mei Rp. 1.000 .000 , bonus yang diberikan bank 30\% dengan saldo rata-rata minimal Rp5.00.000, di asumsikan total dana giro wadiah di bank adalah 500.000.000 pendapatan bank dari penggunaan giro Rp 20.000.000

$$
\begin{aligned}
& \text { Bonus yang diterima } \\
& =(\text { Rp. } 1.000 .000 / 500.000 .000) \times \text { Rp20.000.000 X 30\% } \\
& =\text { Rp. } 12000
\end{aligned}
$$

b. Perkembangan penghimpunan dana dari tahun 2013 sampai dengan 2015 mengalami kenaikan dan penurunan, seperti tabungan yang mengalami penurunan dari tahun 2013 ke 2014 dan mengalami kenaikan lagi di 2015 dari Rp. 23.800.829.000 turun ke 23.636.198.146 dan naik lagi ke Rp. 28.229.308.183 penurunan ini disebebkan kurangnya pengetahuan masyarakat akan bank syariah dan kalah saingnya bank syariah mengambil nasabah, dibandingkan bank konvensional, penghimpunan dana deposito mudharabah selalu mengalami kenaikan dari tahun 2013 sampai dengan 2015 mulai dari Rp. 26.640.870.000 naik Rp. 32.566.780.000 naik Rp. 84.308.380.000 hal ini 
karena para nasabah deposito mudharabah bisa menghitung keuntungan yang akan ia dapat di penghimpunan giro selalu mengalami penurunan dari tahun 2103, turunRp. 2.861.156.561 ditahun 2014, turun menjadi Rp. 2.068.433.598 hingga berakhir di 2015 dengan jumlah Rp. 1.997.130.225 hal ini disebabkan karena sector usaha dipadang di dominasi dengan usaha menengah yang pada umumnya tidak melakukan transaksi dengan cek.

\section{Saran}

a. Agar dapat bersaing dan menjangkau pasar yang besar di Sumatra Barat Bank Nagari Syariah hendaknya menambah cabang di daerah daerah yang tidak terdapat Bank Nagari Syariah dan lebih aktif lagi dalam memperkenalkan Bank Nagari Syariah kepada masyarakat.

b. Bank Nagari Syariah harus mampu bersaing dengan Bank Konvensional mampu Bank Nagari Syariah lainnya dengan cara menetapkan pasar sasarannya (segmentasi pasar), seperti Bank Nagari yang bersifat konvensional segmentasi yang diambil adalah dana daerah dan instansi pemda. seperti rumah sekolah (MAN), Universitas Islam, Instansi yang banyak mengarah ke islam, selain itu juga Bank Nagari Syariah harus mampu

memanfaatkan perannya sebagai Bank daerah Sumatra Barat untuk mengikat Masyarakat menabung dengan prinsip Syariah dalam rangka untuk mencapai penghimpunan dana yang diinginkan.

\section{DAFTAR PUSTAKA}

Ascaraya, (2007). Akad dan Produk Bank Syariah, Raja Grafindo PersadaJakarta.

Arifin, I. Z., \& Marlius, D. (2017). Analisis Kinerja Keuangan PT. Pegadaian Cabang Ulak Karang. https://doi.org/10.31227/osf.io/n2peu

Karim, Adiwarman, (2004).BANK ISLAM, Analisis fiqih dan keuangan. PT.Raja Grafindo Persada: Jakarta.

Marlius, D. (2018). Loyalitas Nasabah Bank Nagari Syariah Cabang Bukittinggi Dilihat Dari Kualitas Pelayanan. Jurnal Pundi. Volume 1. No. 3. Hal.1222. https://doi.org/10.31575/jp.v1i3.60 
Muhammad, M.Ag, (2005). Pengantar Akuntansi Syariah. PT Salemba. Empat Patria, Jakarta.

Pemerintah Republik Indonesia,(2008) Undang-Undang Nomor10 Tahun 1998 Tentang Perubahan Undang-Undang Nomor 7 Tahun 1992. Sinar Grafika, Jakarta.

Syafe'I Antonio, Muhammad. (2001). Bank Syariah dari Teori ke Praktek. Jakarta: Gema Insani

Sulhan, Muhammad. Manajemen Bank Konvensional Dan Syariah .Malang :UIN Malang Press 2008.

Fatwa Dewan Syariah Nasional no : 7 /DSN-MUI/IV/2000 tentang Pembiayaan. Mudharabah.

Wiroso. Akuntansi Transaksi Syariah .Jakarta : Ikatan Akuntan Indonesia. 2011

Ascarya. Akad Dan Produk Bank Syariah .Jakarta : PT Raja Grafindo Persada. Cetakan Ke 3.2011. 